\title{
THE PUBLIC HEALTH SERVICE IN THE CZECH AND SLOVAK REPUBLICS CELEBRATES ITS 60TH ANNIVERSARY
}

\section{Vladimír Bencko}

\author{
Institute of Hygiene and Epidemiology, First Faculty of Medicine, Charles University in Prague, Czech Republic
}

Since the Age of Enlightenment, efforts to prevent disease in Europe have traditionally upheld an acceptably good standard. An implicit factor was the charitable attitude of many physicians and health workers as well as the drive to create the organizational and educational background necessary for the principles of primary prevention to be introduced into actual practice. The Institute of Hygiene of the Czech Faculty of Medicine, now known as the Institute of Hygiene and Epidemiology, 1st Faculty of Medicine at Charles University in Prague, was founded in 1897. An analogical institute at the German Faculty of Medicine in Prague was founded at an earlier date, in 1884.

An important milestone in the development of regional efforts in the field of public health was the establishment of the National Institute of Public Health in 1925. The prominent figures in this process had largely acquired their expertise in the USA; hence a modern school of epidemiology was formed, among its leading lights the eminent Karel Raska, who became the Director of the Division of Communicable Diseases at the WHO Headquarters in Geneva and was one of the authors and managers of the smallpox eradication programme. During the post-war period, leading specialists from Czechoslovakia were trained in epidemiology at the London School of Hygiene and Tropical Medicine, a contact that has remained to this day.

A network of regional public health stations, based on the Soviet model, was set up in 1953. This was followed by the founding of Prague's 3rd Faculty of Medicine at Charles University in 1953.

These days, what we miss most is an expert critical analysis of the successes, failures or potential errors of the public health service over the past six decades, and to even the score are some examples of the various practical applications of our preventive medicine, specifically in the field of epidemiology.

The post-war period involved a campaign against venereal diseases, and decrease in incidence of tuberculosis and, with the much underestimated and close cooperation of the veterinary service, brucellosis.

The former Czechoslovakia was the first country worldwide to start mass anti-polio vaccinations in the early 1960's, thus becoming a precedent for other states, and Czechoslovak doctors participated in the first ever eradication of smallpox; neither of these facts were ever fully appreciated both on the national and international level, although the eradication of smallpox as such was a global event that deserved the Nobel Prize Award.

In the field of non-infectious diseases, there was an extensive epidemiological study of endemic goitre in the late 1940's and early 1950 's, performed by our clinical endocrinologists. The standards presented therein continue to mirror the relatively strict qualitative criteria of current epidemiological studies and have led to the systematic iodination of salt; likewise, this country was among the first to introduce fluoridation of drinking water to prevent caries, again on the basis of a thorough epidemiological study.

Unfortunately, the frequent socio-political changes in this country throughout the last century undeniably disrupted the ongoing system of prevention. Accordingly, the present primary prevention system must adapt to existing social and economic change; much has been achieved, but a backup to the complex structure of existing primary prevention is urgently required.

Czech public health is rooted in the German school founded by Max von Pettenkofer and Robert Koch. The Czech school enriched its predecessor with experimental aspects by providing safe drinking water via Kabrhel's Index and, later, through recognition of the pathophysiological factors expounded in the works of Teissinger, who by the mid-1930's had laid the foundations of present-day biological exposure tests or biomarkers of exposure to environmental toxicants. Several years after the last London smog episode, when the best available health indicator was recorded mortality, Kapalin and Symon were demonstrating adverse environmental effects on growth changes and haematological parameters in exposed children; in this they contributed to the application of more sensitive and sophisticated indicators of health status.

Nonetheless, there are several circumstances in the present day that confound the assessment of the efficacy of primary prevention. Firstly, the effectiveness of the public health system can be rated by its success in preventing health threatening factors which leads us to skating on the thin ice of any kind of conditional. Secondly, the profuse number of exceptions granted in advanced public health legislation has destabilised the system as such. Thanks to the endemic 'granting of indulgences', the quality of surface waters, compromised by heavy pollution from industrial and housing sources and also by inadequate processing in water treatment plants, is trapped in a sea of legal exemptions. Parkinson's laws operated relentlessly on both sides of the Iron Curtain.

From relatively modest beginnings, the public health stations were inflated to immense proportions in the late 1980's, heavily criticised by Western experts on the pitfalls of preventive medicine vis-à-vis the public health system. However, it should be pointed out that although these same critics envied us the institutionalised structure of that sector of the public health service engaged in primary prevention (prevention of disease by altering lifestyle, living conditions and biological resistance) they also warned against its total disruption in the process of attempting to deal with our totalitarian legacy.

Integration of the concepts of primary prevention into the daily activities of all physicians and healthcare personnel is occurring slowly and faces many obstacles on a worldwide scale. This is evident from the problems related to the implementation of global WHO programmes such as the 'Drinking water for all' or 'Health for all by 2000' projects which were anchored in national programmes and adapted to local conditions. The intent of primary prevention as such is suppression of the causes of disease, reduction of its incidence and improvement of life expectancy and quality.

A great amount of money is invested by the Czech government and industry into the environment and health protection as such; we need not glorify nor condemn this fact, since it is a necessity, but let it be noted that the present-day industrial sphere would 
collapse in the event of the incompatibility of deleterious living conditions and human existence as such.

The overall purpose of the drive to educate healthcare professionals and the general public is to promote the fundamental principles and importance of primary prevention in context with medical practice. This covers timely notification of infections, their flexible surveillance, reports on malignity to the national cancer register and, primarily, the necessity of personal engagement in primary prevention programmes.

An important part of public health practice consists of biological monitoring and assessment of the health risk of human exposure to environmental toxins, mostly heavy metals and polyhalogenated hydrocarbons, and of the health aspects of ever increasing risks from traffic emissions. Our sphere of interest involves selected issues of hospital hygiene such as antibiotic resistance, waste disposal from healthcare facilities, indoor environment problems including smoking, and problems encountered in occupational settings.

At present, our public health institutions participate in international multicentre studies organised by the International Agency for Research on Cancer (IARC/WHO), Lyon, and the National Cancer Institute (NCI), Bethesda, concerning the epidemiology of cancer and the ethical aspects of environmental epidemiology and quality of life.

\section{PROFESSOR ERVIN ADAM}

\section{Vladimír Vonka}

\section{Institute of Hematology and Blood Transfusion, Prague, Czech Republic}

Last November, a few days after his 90th birthday, Dr. Ervin Adam, a member of the Journal Editorial Board and Professor of Epidemiology at Baylor University in Houston, received the Czech Mind - Patria Award. Former Czech citizens are presented with this Award by the Czech government in recognition of outstanding achievements in the field of science or arts abroad.

Dr. Adam was born on November 7, 1922 in Rakov. During World War II, he spent nearly two years in concentration camps. After the end of the war in 1945, he started his medical studies at Charles University. Immediately after his graduation in 1951, he began to work at an Clinic of Infectious Diseases then headed by renowned professor Procházka. Dr. Adam exhibited his extraordinary abilities and within few years became one of the leading authorities in the field of infectious diseases and in 1954, he assumed the deputy head position. In the $1950 \mathrm{~s}$, the fight to eradicate poliomyelitis started, and Dr. Adam became one of the leading specialists in polio eradication.

Dr. Adam participated in testing of inactivated and live vaccine against poliomyelitis and together with his late wife, Dr. Vlasta Adamová, played a decisive role in eradication of this disease in Czechoslovakia. Despite their outstanding contribution, they were expelled from the Paediatric Faculty of Charles University for political reasons.

After expulsion from the university, Dr. Adam joined the Institute of Sera and Vaccines where he established the Department of Clinical Epidemiology. He was involved in the research of effectiveness and safety of biological preparations, and developed and applied a new testing methodology widely used by many institutes abroad. After the Soviet invasion of Czechoslovakia in 1968 , he left the country.
Like other institutions engaged in the field of public health we also try to continue meaningful cooperation on the international scene with WHO, IPCS, Science for Peace and Security/NATO, and others. A certain hope open to us in the future is that the steadily rising cost of medical treatment will urge responsible political bodies to recognise the importance of primary prevention from both cost/benefit and evidence-based aspects, leading to the introduction of associated principles in national healthcare policy.

Apart from the expected development of non-infectious epidemiology, there exist a number of potential health risks arising from genetic manipulation in microbiology, pharmaceutical microbiology and biotransformation of persistent xenobiotics; all of which are involved in solutions to waste disposal issues.

The problems and tasks of the future require unrestrained cooperation of public health and epidemiological branches. Past experience from other fields of science shows that the fastest progress can be expected when individual disciplines overlap - in this case, the methodical application of molecular toxicology in environmental epidemiology.

The future focus of interest in our public health service remains on the development of novel strategies for analysis of health risks in the prevention of disease: this will be the major public health priority in the 21 st century.

After a short time spent at McGill University in Montreal, Dr. Adam received an invitation from Dr. Joseph Melnick, who then headed Department of Virology and Epidemiology at Baylor University in Houston. Dr. Adam became a Visiting Professor of Epidemiology at the Baylor College of Medicine, at that time the world's leading center of virus research. He began to study the role of viruses in pathogenesis of cancer especially in cervical carcinoma, and later on the role of viruses in the development of atherosclerosis.

He achieved outstanding results, published in prominent journals and received many prestigious awards. In 1983, he was appointed Professor of Epidemiology at the Baylor College of Medicine and in the same year also Professor of Gynaecology at the same College. He was elected a Fellow of prestigious scientific societies such as the American Society of Epidemiology and the American College of Epidemiology.

In 1996, he was elected a member of the Learned Society of the Czech Republic. In 2005, he received the Award of the Year in the Recognition of His Life-Long Contribution in Study of Oncogenic Viruses from the International Papillomavirus Society. He still keeps very close ties with the Czech Republic. After the velvet revolution in 1989, he and his wife were granted pensions from the Czech government and used all this money to fund scholarships for medical students at Charles University.

Despite his advanced age, professor Adam still works at the Department of Virology at Baylor College of Medicine, recently renamed the Department of Molecular Virology and Microbiology. He is involved in the research project aimed at women exposed to hormone therapy during pregnancy and the incidence of malignant tumours in their offspring. Let us point out, that professor Adam has a Hirsch Index of 40. 